\title{
Parameterising resuspension in aquaculture waste deposition modelling
}

\author{
Thomas P. Adams ${ }^{1, *}$, Kevin Black ${ }^{2}$, Kenny Black ${ }^{1}$, Trevor Carpenter ${ }^{3}$, \\ Adam Hughes ${ }^{1}$, Helena C. Reinardy ${ }^{1,4}$, Rebecca J. Weeks ${ }^{1}$ \\ ${ }^{1}$ Scottish Association for Marine Science, Scottish Marine Institute, Oban PA37 1QA, UK \\ ${ }^{2}$ Partrac Ltd., Suite B3D, Milburn House, Dean Street, Newcastle-upon-Tyne, NE1 1LE, UK \\ ${ }^{3}$ Aqua Numerical, Lorn Road, Oban PA37 1QG, UK \\ ${ }^{4}$ Department of Arctic Technology, University Centre in Svalbard, 9171 Longyearbyen, Norway
}

\begin{abstract}
Sustainable expansion of global aquaculture depends on a thorough understanding of environmental impacts. Open-water culture operations produce waste food and faeces, the benthic impacts of which are a focus of regulation. Seabed interactions of wastes are complex depending on current velocity, seabed substrate and waste material characteristics. The accuracy achieved in modelling intensity and spatial extent of impacts is contingent upon the representation of this interaction and its implications for resuspension. We used benthic flumes to study resuspension processes at 11 salmon aquaculture sites, covering a range of sediment types. Erosion rates and critical entrainment stress were computed at the cage edge and between 100 and $500 \mathrm{~m}$ away, characterising seabed erodibility in highly impacted and less impacted sediments. Heavily impacted cage-edge sediments had an erosion threshold (mean $0.02 \mathrm{~N} \mathrm{~m}^{-2}$ ) that was an order of magnitude lower, and markedly less heterogeneous, than that of nearby less impacted sediments (mean across sites $0.19 \mathrm{~N} \mathrm{~m}^{-2}$ ). This likely reflects a seabed which was smothered by waste material close to the depositional centre. Further out, the covering of waste material is less continuous, thinner, and more admixed with underlying sediments. Bed erosion rates were found to be a linear function of excess stress. The results provide important information on how benthic flumes can be deployed to collect spatial and temporal data for parameterisation of erosion and entrainment processes in numerical waste transport simulation models such as DEPOMOD, and the comparatively large field-based dataset should contribute to the goal of allowing a more realistic representation of particulate waste in these models.
\end{abstract}

KEY WORDS: Aquaculture $\cdot$ Deposition $\cdot$ Benthic impacts $\cdot$ Resuspension $\cdot$ DEPOMOD

\section{INTRODUCTION}

As the aquaculture industry seeks to achieve sustainable expansion (World Bank 2013, Scotland Food \& Drink 2017), it also seeks to minimise its environmental impacts (Niklitschek et al. 2013, Tett et al. 2018). Modelling can assist operators in meeting regulatory requirements and assessing operational risks, ensuring aquaculture sites are not placed in areas where they will have adverse (or extensive) environ-

\footnotetext{
*Corresponding author: tom.adams@sams.ac.uk
}

mental impacts (SEPA 2019b). It can also provide a basis on which regulators can make a balanced assessment of existing operations (Gentry et al. 2017), helping to inform regional management objectives (Salama \& Rabe 2013, Adams et al. 2016, Sandvik et al. 2016).

A specific challenge facing the industry is the fate of particulate matter released either as waste feed or as faeces of the farmed animals. These contain organic matter, which can enrich the seabed environ-

() The authors 2020. Open Access under Creative Commons by Attribution Licence. Use, distribution and reproduction are unrestricted. Authors and original publication must be credited. 
ment (Pearson \& Rosenberg 1978, Kalantzi \& Karakassis 2006, Hargrave et al. 2008), and chemical compounds used to treat fish against parasites, which can have impacts on non-target organisms (Veldhoen et al. 2012, Bloodworth et al. 2019). Waste feed and faeces differ in carbon content and chemical profile as well as in their characteristic size, shape and density. Once released from a fish farm cage, waste particles are initially transported in suspension, carried by the movement of water currents and turbulent processes. Once they reach the seabed, several things may occur. If flow rate is sufficiently high (and seabed shear stress is correspondingly high), particles placed on the seabed may be eroded and reenter the water column (Amos et al. 1992a, Droppo et al. 2007, Law et al. 2016, Law \& Hill 2019). If particles remain on the seabed for a sufficiently long time, their constituents consolidate on the seabed (Bahr et al. 2001), a biofilm may develop (Droppo et al. 2007) or sediment characteristics may become altered by benthic organisms (Rhoads \& Boyer 1982). Further layers of sediment placed on top have the effect of consolidating underlying layers, increasing the critical level of seabed shear stress required to erode this matter (Masaló et al. 2008) while also potentially covering it. In high-flow locations, waste matter is transported further during the initial settlement phase. However, where seabed shear stress at peak tidal flow exceeds the critical level for erosion, resuspension can potentially account for a large component of the total distance that waste matter is transported from farm cages (Giles et al. 2009).

Many models suitable for the simulation of the fate of waste feed and faeces have been developed over the last 2 decades. A key example is DEPOMOD (AutoDEPOMOD and NewDEPOMOD; Cromey et al. 2002a, Cromey \& Black 2005, NewDEPOMOD Development Team 2019), which has been adapted and used extensively by the global aquaculture industry to study and regulate waste material production in a diverse range of settings and production organisms (Weise et al. 2009, Cromey et al. 2012, Keeley et al. 2013, Chang et al. 2014). Sediment transport can also be implemented within regional hydrodynamic models (Lee et al. 2015, Bannister et al. 2016, Broch et al. 2017). In either case, it is essential to accurately describe and model particle-bed interactions and resuspension processes. However, in spite of a wealth of studies on sediment erosion over the last 60 yr (e.g. Ariathurai \& Arulanandan 1978, Mehta \& Partheniades 1979, Thorn \& Parsons 1980, Villaret \& Paulic 1986, Lavelle \& Mofjeld 1987, Houwing 1999, Amos et al. 2004, Thompson et al. 2011, Law et al. 2016, Carvajalino-Fernández et al. 2020), there is no means of predicting from first principles the critical entrainment stress (or bed erosion rate) for sediments such as cohesive muds or organic-rich fish waste (Sutherland et al. 1998b), for which the classical Shields diagram (Shields 1936) may not apply. On a practical level, this means these parameters must therefore be measured.

Benthic flumes are marine instruments designed specifically to measure the surface erosion characteristics of bottom sediments directly in situ (Amos et al. 1992b, 1996, Black \& Cramp 1995, Black \& Paterson 1997, Thompson et al. 2011). We used 2 such devices to make in situ measurements of the bed erosion properties of undisturbed, organically impacted sediments beneath and around active fish farm pens. Flumes measure the benthic vertical flux aspect of suspended sediment transport, which is relevant to understanding potential far-field (FF) transport and possible environmental impacts of the organic waste of concern to the regulator. Highly pelleted waste mounds can move via saltation and bed load (Sutherland et al. 2006), but such transport does not impact FF areas and thus is not relevant here.

FF experiments were carried out using a full-size flume, and near-field ( $\mathrm{NF}$, cage edge) measurements were made using a smaller device. A combined analysis of these observations provides a robust empirical basis for updating the parameterisation and configuration of resuspension processes in models simulating waste dispersion. We discuss these recommendations in the context of the redevelopment of the NewDEPOMOD software.

\section{MATERIALS AND METHODS}

\subsection{Field survey programme}

Two field campaigns were carried out, both on the west coast of Scotland. This is a key salmon production region which plays host to around 200 farm sites, primarily located within sheltered fjordic areas or close to islands. The study area was slightly to the south of mid-latitude within the broader production area. The surveys were carried out at different times due to vessel availability and presence of suitable conditions for deployments. All survey locations are shown in Fig. 1. Meteorological conditions were generally very calm throughout the surveys, and only 1 deployment (1_FIU2 during the FF survey) had to be aborted (and repeated) due to vessel movement. 


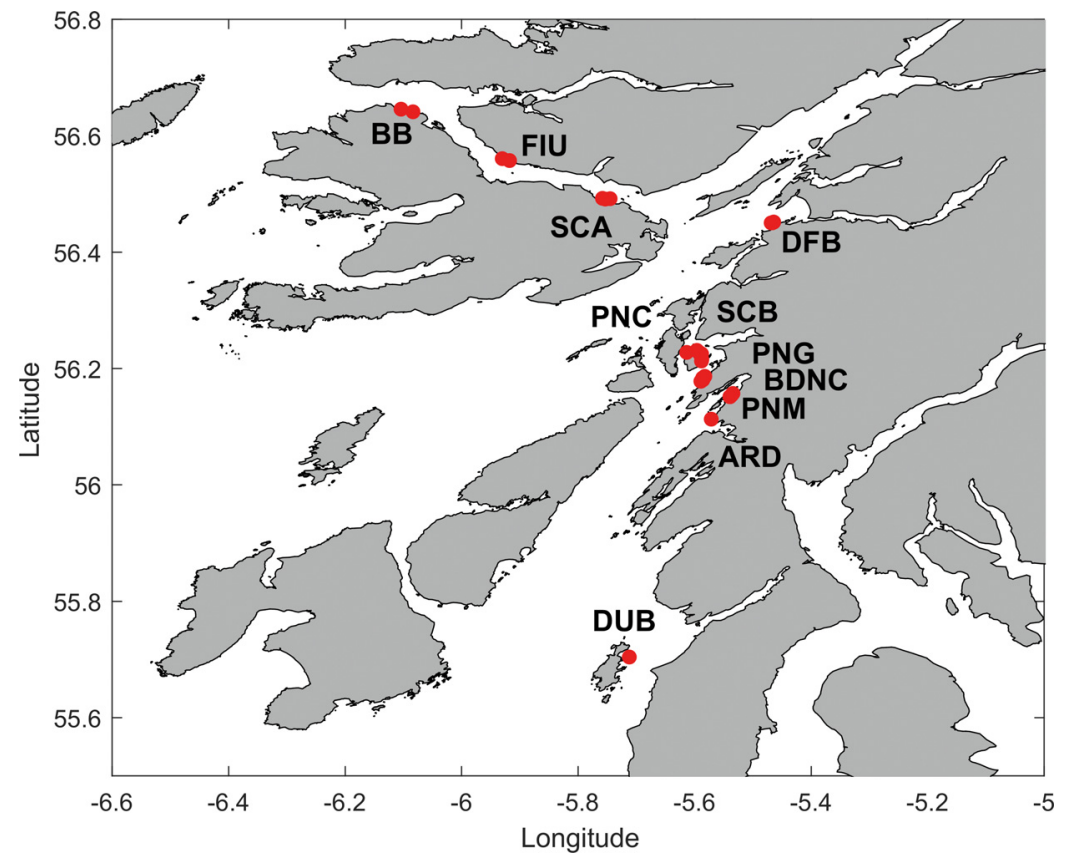

Fig. 1. Study sites, showing site codes (full names detailed in Table 2)

frozen after collection. For analysis, the samples were defrosted, slices were taken at the surface $(0-1$ and $1-2 \mathrm{~cm})$ and the slices were combined and homogenised; $10 \mathrm{ml}$ samples were weighed, dried for $24 \mathrm{~h}$ at $60^{\circ} \mathrm{C}$ and reweighed. Dry bulk density was calculated as dry wt $\mathrm{vol}^{-1}\left(\mathrm{~kg} \mathrm{~m}^{-3}\right)$. To determine loss on ignition (LOI), $0.5 \mathrm{~g}$ of dried, ground and sieved sediment was ashed $\left(250^{\circ} \mathrm{C}\right.$ for $16 \mathrm{~h})$. When cooled, the crucibles were reweighed. Sediments were then heated to $500^{\circ} \mathrm{C}$ (Loh 2005) for $16 \mathrm{~h}$ and weighed again when cool. Organic matter percentage was computed from data provided within the LOI methodology (Mudroch \& Azcue 1995).

\subsection{Erosion experiments}

\subsubsection{Benthic flumes}

An FF survey of farm sites took place in August 2013 aboard the SEPA RV 'Sir John Murray', using the Voyager II flume. Flume deployments were carried out as close to the fish farm infrastructure as was safe to do so with a large vessel, but generally sufficiently close as to be impacted by the farm (ranging between 100 and $500 \mathrm{~m}$ from the cage edge). Altogether, 27 successful scientific deployments (31 including trials and unsuccessful deployments) were made (see Supplement 1 at www.int-res.com/articles/ suppl/q012p401_supp1.xlsx). During this survey, 2 flume deployments and a single grab sample were made at each point sampled.

An NF survey took place in May 2014 using a smaller vessel, the Scottish Association for Marine Science (SAMS) RV 'Seol Mara', directly moored to fish farm cage groups, and used the smaller Voyager I flume. This consequently facilitated testing of nominally highly impacted sediments close to the central depositional zone of sites. Seabed sediments tested were impacted by feed and fish waste material to a greater degree compared to the previous (FF) survey. A total of 13 successful deployments (19 deployments including trials and those where sediment/bathymetry were unsuitable) were carried out (Supplement 1).

\subsection{Grab samples}

Grab samples were collected to assess seabed sediment composition at the survey sites. Samples were
Benthic flumes are a method by which the erosion potential of marine sediments may be studied in situ. They operate by enclosing a volume of water at the seabed and then generating a controlled flow stress across the sediment surface. Their use spans nearly 3 decades, since the seminal early work of Amos et al. (1992b). In this study, 2 different benthic annular flumes were used to investigate the effect of shear stresses on a range of seabed substrates: the Voyager I and Voyager II systems (Thompson et al. 2011). Key specifications and features of the 2 flumes are detailed in Table 1. Both flume instruments were deployed in the same way: the flume was slowly lowered to the bed and then left still on the seabed for 5 to $10 \mathrm{~min}$. Fluid motion was induced by the rotation of internal paddles; paddle rotation was then increased in a stepwise manner through a series of acceleration ramps with the purpose of sequentially exposing the sediment surface to higher stresses (Amos et al. 1992b, 2004, Sutherland et al. 1998a,b). Once the end velocity was reached, the paddles were stopped immediately, allowing for sediment deposition to occur. Time series of turbidity (via optical backscatter sensors [OBSs] flush-mounted in the flume wall) and paddle rotation frequency were recorded by both flumes. Additionally, flow velocity was recorded within Voyager II.

Voyager I is a compact mini-flume. An advantage of this flume is that it can be deployed using a small vessel, which can accordingly be moored directly 
Table 1. Specification and features of the 2 benthic flumes used in the study. W: width; H: height; OBS: optical backscatter sensor

\begin{tabular}{|c|c|c|}
\hline & Voyager I & Voyager II \\
\hline Survey & Near-field & Far-field \\
\hline Diameter & $0.245 \mathrm{~m}$ & $2.2 \mathrm{~m}$ \\
\hline Exposed bed area & $0.139 \mathrm{~m}^{2}$ & $0.966 \mathrm{~m}^{2}$ \\
\hline Channel & Single annular channel, $0.12 \mathrm{~m}(\mathrm{~W})$ & Single aluminium channel; $0.3 \mathrm{~m}(\mathrm{H}), 0.15 \mathrm{~m}(\mathrm{~W})$ \\
\hline Structure & $\begin{array}{l}\text { External frame with skirt (limiting depth frame } \\
\text { sinks into bed) }\end{array}$ & $\begin{array}{l}\text { Skirt around outer channel wall, sink to } 0.045 \mathrm{~m} \\
\text { into bed; flushing of water via } 8 \text { lid sections }\end{array}$ \\
\hline Paddles & 4, mounted at cardinal points on rotating lid & $\begin{array}{l}\text { 8, equidistantly spaced on chain drive, } 210 \mathrm{~mm} \\
\text { above nominal bed level }\end{array}$ \\
\hline OBS & 1 (50 mm above nominal bed level) & $3(85,145$ and $200 \mathrm{~mm}$ above nominal bed level $)$ \\
\hline Velocimeter & - & $\begin{array}{l}\text { Along-channel, across-channel and vertical } \\
\text { directions, } 0.15 \mathrm{~m} \text { above the nominal bed level }\end{array}$ \\
\hline Additional features & - & $\begin{array}{l}\text { Automated syringe sampling system (for OBS } \\
\text { calibration; not used); video recorder, two } 24 \mathrm{~V} \\
\text { light-emitting diode lamps (not used) }\end{array}$ \\
\hline
\end{tabular}

alongside farm cages to collect data at the cage edge during the NF survey (an environment rather difficult to access otherwise) (Fig. 2a). Voyager II (Thompson et al. 2011) is a larger version of the mini-flume and works on the same principles; however, it is more sophisticated (Fig. 2b). Its size requires deployment from a larger vessel, which must anchor away from farm infrastructure. It is therefore best suited to making observations some distance away from cages and was used during the FF survey.

Details on the calibration of the bed shear stress calculations for both flumes are detailed in Supplement 2 at www.int-res.com/articles/suppl/q012p401_ supp2.pdf. A detailed description of the Voyager II/ Sea Carousel flume designs is given by Amos et al. (1992b).

\subsubsection{Turbidity sensor calibrations}

The on-board OBSs record raw data as a voltage; this requires conversion into scientific units $\left(\mathrm{mg} \mathrm{l}^{-1}\right.$ ) of sediment concentration (turbidity). A series of calibrations were undertaken using surface scrapes (upper $1 \mathrm{~cm}$ ) from bottom sediment samples collected at each site using a van Veen grab. Samples were collected, bagged and frozen during both surveys (photographs of each grab were taken). For each calibration concentration, reference standards were made by mixing a known dry mass of sediment into a known volume of seawater. Eight standards were made up for each site, from zero to many times the concentration, corresponding to critical erosion. The OBS was sequentially exposed to these suspensions and least-squares regression analysis used to generate an equation relating sensor voltage to sediment concentration (see Supplement 2).

\subsubsection{Data analysis}

The suspended sediment $(S)$ time series for both surveys (and flume types) were initially inspected visually for quality, and any obvious outliers were removed and stored in a quality control log. Any background (pre-existing, i.e. generated by flume touchdown) turbidity was subtracted. For all time series, the data were time averaged every $20 \mathrm{~s}$ to eliminate high-frequency short-term variability in the record (Widdows et al. 2007).

For Voyager II, the time series of $S$ concentration $\left(\mathrm{mg} \mathrm{l}^{-1}\right.$ ) and flow velocity $u$ were recorded during each experiment. The $S$ time series was then trans-
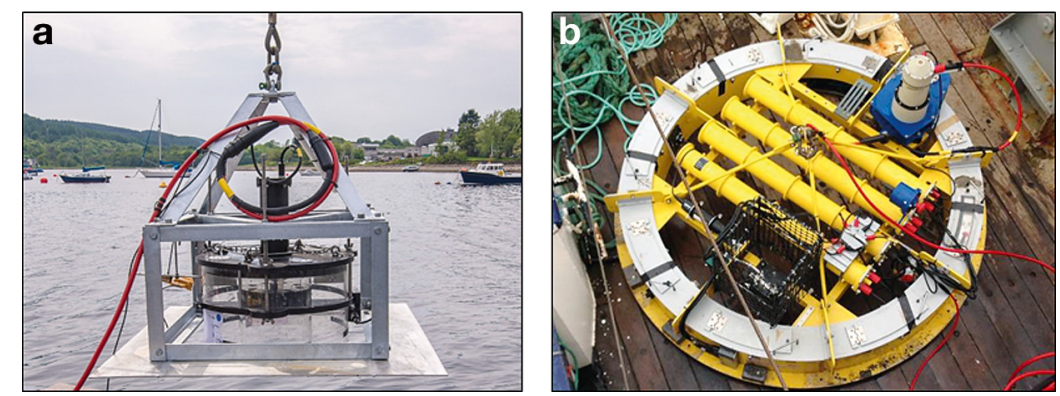

Fig. 2. Benthic flumes used in the study. (a) Voyager I mini-flume; (b) plan view of the Voyager II benthic flume 
formed into SI units $\left(\mathrm{kg} \mathrm{m}^{-3}\right)$. Details of the conversion of flow velocity into equivalent bed stress $\left(\tau_{0}\right.$, $\mathrm{N} \mathrm{m}^{-2}$ ) are provided in Table $\mathrm{S} 1$ in Supplement 2 (Amos et al. 1992b, Black et al. 2016). Voyager I does not record flow velocity within the annulus in situ, and bed stress is derived from paddle rotation rate/flow data using the method presented in Supplement 2. For both devices, an algorithm is applied to the stress time series to account for stress reduction at high $S$ values.

From these data, metrics characterising seabed stability were derived, including (1) eroded mass (EM, $\mathrm{kg}$ ), using the flume volume $V_{i}(2)$ instantaneous erosion rate $\left(\mathrm{kg} \mathrm{m}^{-2} \mathrm{~s}^{-1}\right)$ over the first minute following a ramp in bed stress, using the values for flume area and the time interval between successive data points; (3) cumulative EM $(\mathrm{kg})$, from which a record of the total mass of sediment eroded $\left(\mathrm{EM}_{\mathrm{max}}\right)$ per time step $(\Delta t)$ was made; and (4) erosion depth $(z)$ estimation defined by $z=\mathrm{EM} / \rho_{\mathrm{s}} A$ (values for $\rho_{\mathrm{s}}$ were taken from measurements of surface dry bulk density recorded from samples collected at each site; $A$ is footprint area of flume in $\mathrm{m}^{2}$ ). A record was kept of the maximum depth of erosion $\left(z_{\max }\right)$ per time step, $\Delta t$.

\subsection{Analysis}

\subsubsection{Computation of critical entrainment stress}

Computation of the critical entrainment stress metric can vary according to the researcher (Sutherland et al. 1998b provide a useful review of 4 different approaches). The Voyager I flume has the OBS fixed a small distance $(25 \mathrm{~mm}$ ) above the sediment-water interface and imposes many more bed stress time steps per erosion run (twice as many as the Voyager II system), starting at $0 \mathrm{~N} \mathrm{~m}^{-2}$ and incrementing at steps of $0.01 \mathrm{~N} \mathrm{~m}^{-2}$. The proximity of the OBS and the higher-resolution erosion profile permits a direct view of the stress when sediment first appears in suspension and therefore does not need to involve any statistical (regression) analysis. This approach has been advocated elsewhere for high-porosity, relatively low shear strength intertidal mudflat sediments (Widdows et al. 1998). To provide a consistent basis for comparability of results, we defined $\tau_{0 \text {, crit }}$ as the bed stress when the concentration of sediments within the annulus was first observed to be $10 \mathrm{mg} \mathrm{l}^{-1}$ over background (with the requirement that this concentration was exceeded for a period of $30 \mathrm{~s}$ ). This, we consider, corresponds to a very small but finite exceedance of the actual moment of true incipient entrainment.
The configuration of the Voyager II flume, with the lowermost OBS farther above the sediment bed (50 $\mathrm{mm})$ and fewer bed stress time steps, does not allow for this approach to the estimation of $\tau_{0, \text { crit }}$ to be followed. Therefore, a regression method based on the use of erosion depth was found to be the most robust method (Mehta \& Partheniades 1982) for FF flume deployments. Relative to the method used for the Voyager I (NF) sites, this approach slightly overestimates $\tau_{0, \text { crit, }}$ but the difference is not judged to be significant.

\subsubsection{Relationships with sediment characteristics}

Comparison was made between critical entrainment stress and particular sediment characteristics (dry bulk density, median grain size, LOI and organic matter content) in NF samples, as separate surveys and with the data grouped together. At each sample point in the FF survey, 1 grab sample and 2 flume deployments were made. For plotting and computation of regressions using FF values, it was assumed that both flume deployments at each location corresponded to the same grab sample values.

\subsubsection{Computation of equivalent current velocities}

Critical erosion stress values were transformed into equivalent critical mean current velocities $\bar{u}_{\text {critt }}$. at $2 \mathrm{~m}$ above the bed (the reference velocity height within AutoDEPOMOD) using $u_{(z)}=u_{*} / \mathrm{k} \ln \left(z / z_{0}\right)$ where $u_{*}=\sqrt{\tau_{0, \text { crit }} / \rho}$, with $\rho=1026.9 \mathrm{~kg} \mathrm{~m}^{-3}$ (assuming a temperature of $10^{\circ} \mathrm{C}$ and a salinity of 35 PSU). $\kappa=0.4$ is the von Kármán constant, and a value of $z_{0}=0.0002 \mathrm{~m}$ was assumed, approximating a smooth muddy seabed (Cromey et al. 2002b). Black et al. (2016) found that bed roughness lengths near to the sites varied, with a mean of $0.00003 \mathrm{~m}$ at hydraulically smooth sites (almost all those here) and 2 transitional rough sites with a mean of $0.054 \mathrm{~m}$. The impact of this variation on resuspension is considered in Section 4.

\subsubsection{Resuspension rates of impacted bed material}

Computation of EM in particle-tracking models requires the definition of a relationship between bed erosion rate $\left(\varepsilon, \mathrm{kg} \mathrm{m}^{-2} \mathrm{~s}^{-1}\right)$ and ambient (or applied) bed stress $\left(\tau_{0}\right)$ to resuspend bed material into the flow. The form of this relationship has been found by 
others to vary according to, among other things, geographic location, sediment stratification, density and sediment type (composition). Hypothesised relationships include linear and power law expressions relating $\varepsilon$ to (1) absolute $\tau_{0, \text { crit, }}$ (2) excess bed stress where the critical erosion threshold is depth dependent $\left(\tau_{0}-\tau_{0, \text { crit }}(z)\right)$ (Ariathurai \& Arulanandan 1978, Mehta \& Partheniades 1979, Thorn \& Parsons 1980, Kusuda et al. 1985, Villaret \& Paulic 1986, Lavelle \& Mofjeld 1987, Houwing 1999, Sanford \& Maa 2001, Amos et al. 2010). Historically, AutoDEPOMOD has used a linear relationship between $\varepsilon$ and excess bed stress. Amos et al. (2010) investigated the application of this spectrum of relationships to data from Venice Lagoon, using $\mathrm{R}^{2}$ as their fit metric. We followed their approach, using data collected in both the NF and FF surveys, to identify the bestfitting (highest $\mathrm{R}^{2}$ ) description of benthic flux for our sites.

\section{RESULTS}

\subsection{Sediment classification}

Bed types at the survey sites consisted primarily of a poorly sorted multi-modal mixture of glacigenic/ glacimarine silt and sand, from coarse to very fine and of high porosity (typically in excess of $70 \%$ ). At one site (Ardifuir), 1 sample was of gravel, although a number of other sites are also coarse. All sediments were organically enriched, although FF samples (Fig. 3a-c) exhibited LOI values mostly less than $10 \%$, contrasting with NF samples (Fig. $4 \mathrm{a}-\mathrm{c}$ ), which were $>10 \%$ and commonly $>20 \%$. These values are higher than expected in this locality; at Dunstaffnage (a relatively sheltered, slow-moving site), LOI $200 \mathrm{~m}$ away from the cages reaches around $2 \%$ (data not shown).

A comparison between the 2 survey time points was not made, due to the focus on different distances from the cage locations during each survey. No clear or consistent spatial patterns were seen between sites (sites arranged north to south in Figs. $3[\mathrm{FF}] \& 4$ $[N F])$, and variation within sites was in some cases quite high. Complete numerical results of the sediment sample analysis are contained in Supplement 1.

\subsection{Benthic flumes and erosion experiments}

\subsubsection{Erosion of less impacted (FF) sediments}

The 2 benthic flumes were successfully deployed. On occasion, the seabed ground conditions prevented a seal forming, which voids any data collected, and one site was overly coarse and not suited to use of the technology.
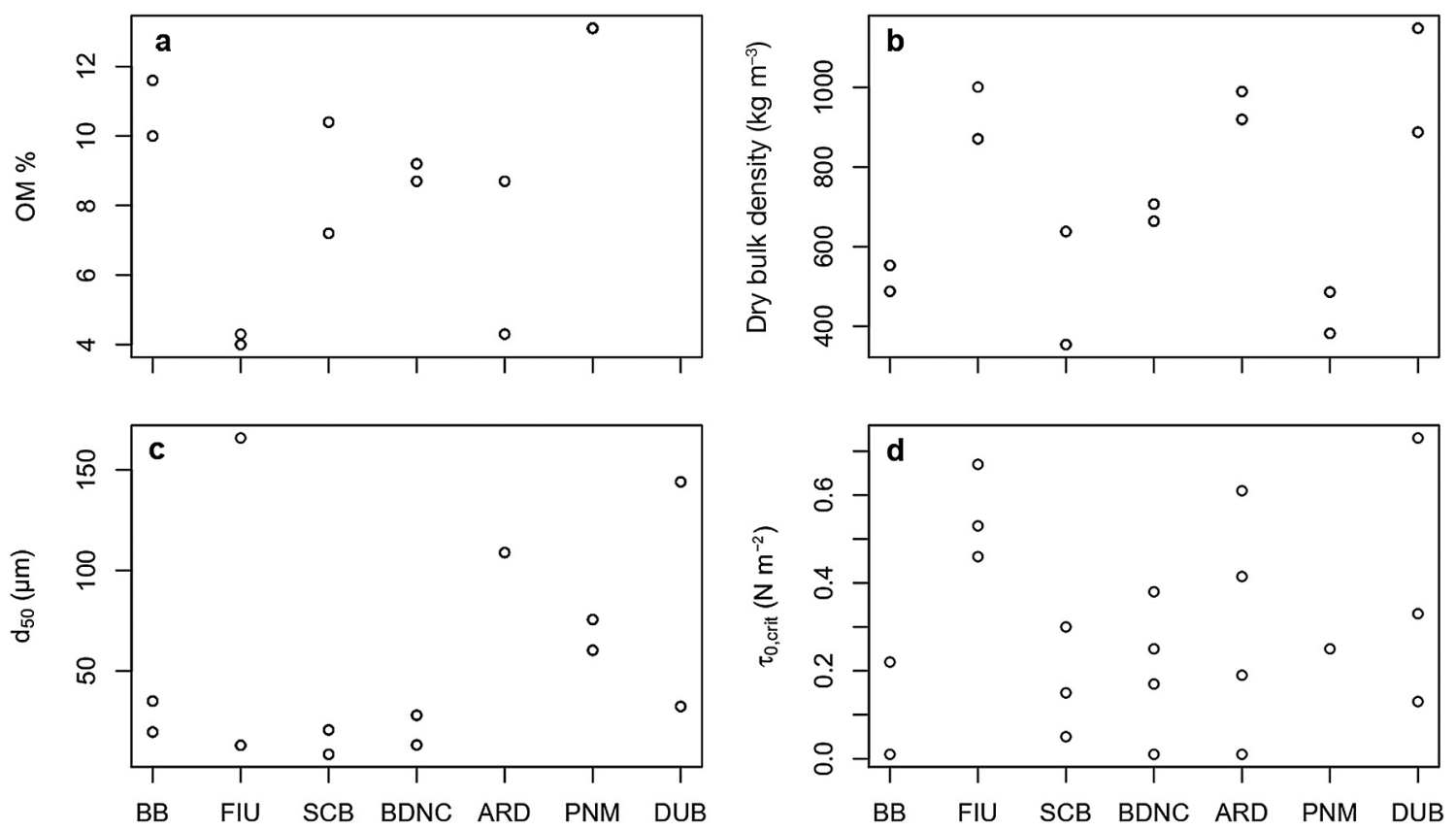

Fig. 3. Far-field survey data, with data points grouped by survey site (ordered north to south). (a) Organic matter (OM) percentage; (b) dry bulk density; (c) median grain size $\left(\mathrm{d}_{50}\right)_{i}(\mathrm{~d})$ critical entrainment stress $\left(\tau_{0, \text { crit }}\right)$. Site codes defined in Table 2 

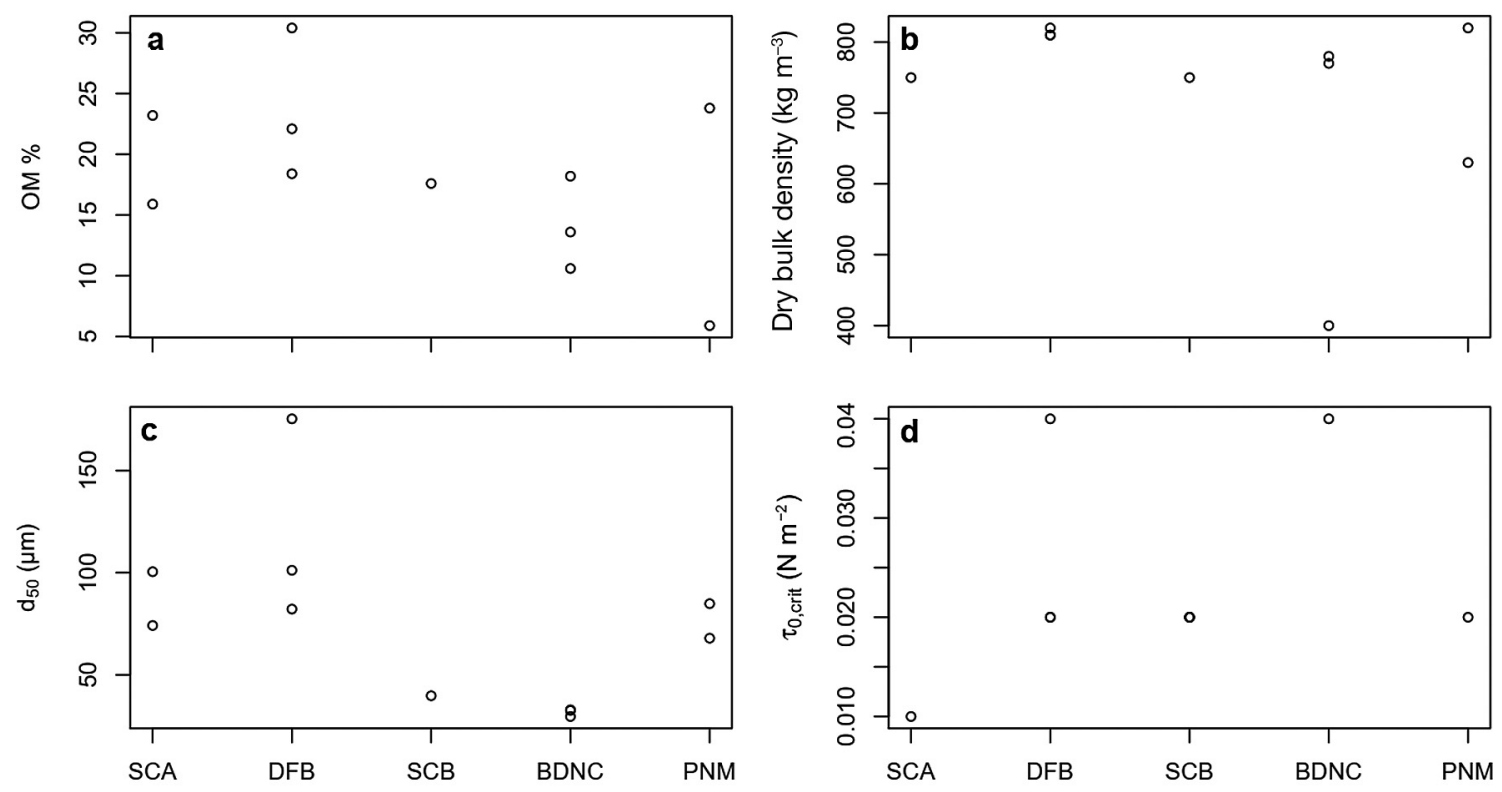

Fig. 4. Same as Fig. 3 but for near-field survey data

An example of the time series of measured (and derived) parameters at Durmyon Bay 1_DUB3 on 29 August 2013 from FF survey deployments of the Voyager II flume is presented in Fig. 5. As seabed erosion within the flume annulus occurred, sediments were entrained into suspension during each time step (i.e. during each applied constant voltage/velocity/stress). Increases in applied voltage resulted in increased paddle rotation speed and the mass of suspended particulate matter (Fig. 5a). EM broadly increased over time (Fig. 5b), while instantaneous erosion rate peaked in response to each increase in applied voltage (Fig. 5c), and the corresponding eroded depth time series (Fig. 5d) mirrored the EM time series effectively. In this specific example, increases in flow velocity within the annulus induce step-wise erosion, and concentration values rose to a maximum of ca. $330 \mathrm{mg} \mathrm{l}^{-1}$. Sediment deposition was evident when the motor is switched off (not shown here). Peak (instantaneous) erosion rates rose systematically with increases in applied bed shear stress to ca. $5 \times 10^{-4} \mathrm{~kg} \mathrm{~m}^{-2} \mathrm{~s}^{-1}$, and the pattern of erosion depicted consistent Type I (asymptotic) erosion. The maximum erosion depth was $\sim 0.12 \mathrm{~mm}$. (a)

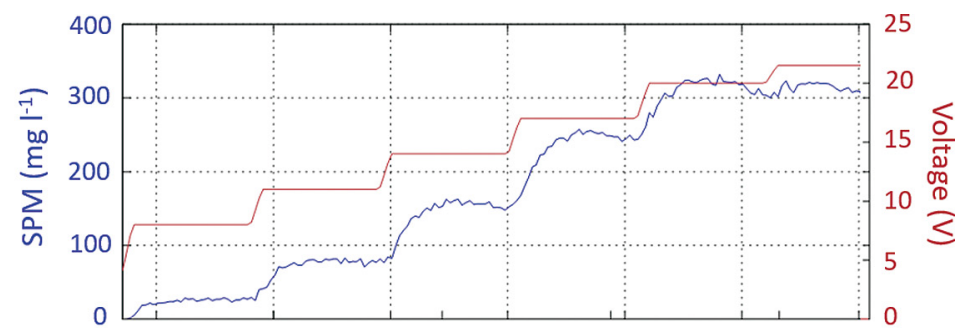

(b)

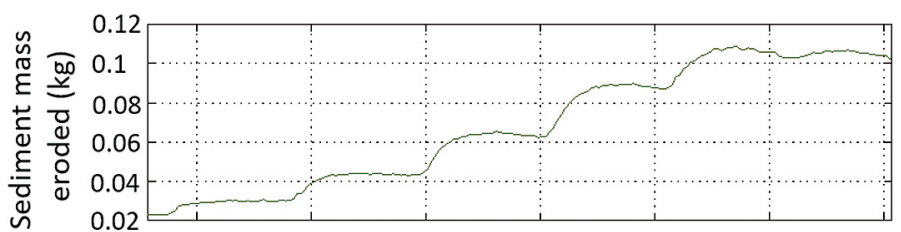

(c)

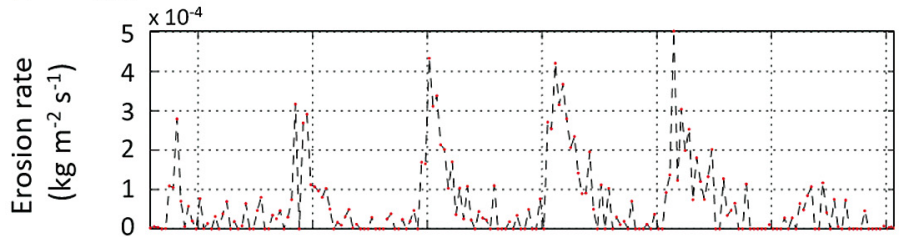

(d)

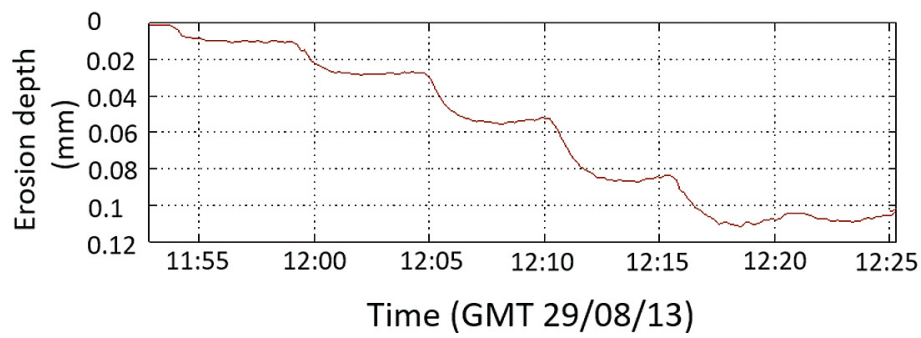

Fig. 5. Durmyon Bay 1_DUB3 (far-field) on 29 August 2013. (a) Applied voltage and total suspended solids concentration; (b) mass of suspended sediment eroded; (c) instantaneous erosion rates (computed every 20 s), indicating Type 1 erosion; (d) depth of erosion. SPM: suspended particulate matter 
Table 2 summarises derived critical entrainment stress values $\left(\tau_{0, \text { crit }}\right)$ for the FF sites; values for particular samples in FF survey 1 are presented by site in Fig. 3d and given numerically in Supplement 2. Five of the FF sample points were classified as having no measureable (or very low) critical entrainment stresses, where the regression line essentially goes through or very close to the origin; $\tau_{0 \text {, crit }}$ values ranged from 0 to $0.73 \mathrm{~N} \mathrm{~m}^{-2}$. The opportunity to undertake multiple flume deployments at each site revealed heterogeneity in threshold stresses.

\subsubsection{Critical entrainment stress of highly impacted} (NF) faeces-rich sediments

Measurements of organic content (LOI) indicated percentages of up to $26.1 \%$ for NF sites (Fig. 4), indicative of a highly impacted situation. The flume runs enabled direct measurement of the critical entrainment stress, and erosion through depth, of surficial sediments close to the depositional centre of the fish farm apparatus. Under the definition used here for the critical entrainment condition (the stress at which the concentration of sediment within the flume waters is $\geq 10 \mathrm{mg} \mathrm{l}^{-1}$ over background), welldefined critical entrainment conditions were identified in all (11) successful time series except at 4 sites where flume leakage issues were encountered.

Results from 2_DFB2 (Dunstaffnage Bay, 29 May 2014) are presented in Fig. 6. This shows an incremental (13-step) stress profile $\left(\Delta \tau_{0}=0.011 \mathrm{Nm}^{-2}\right.$, step duration $5 \mathrm{~min}$, maximum $\tau_{0}=0.14$ ) applied to the sediment-water interface. The above critical stress criterion is met at a stress of $0.04 \mathrm{Nm}^{-2}$.

Critical stress values derived from the time series for NF survey sites are summarised in Table 2, with values for individual samples categorised by site in Fig. 4d and provided numerically in Supplement 2. These range from 0.01 to $0.04 \mathrm{~N} \mathrm{~m}^{-2}$, and there is notably less heterogeneity in the spread of values for sites. These stress values give equivalent critical current velocities $\bar{u}_{\text {crit. }}$ at $2 \mathrm{~m}$ above bed ranging from 0.07 to $0.14 \mathrm{~m} \mathrm{~s}^{-1}$ (modal value $0.10 \mathrm{~m} \mathrm{~s}^{-1}$ ).

Where data are available from FF and NF surveys (Shuna Castle Bay, Bagh Dail Nan Ceann and Port na Moine), the NF values are an order of magnitude lower, indicative of a gradient (increase) in stability away from the farm.

\subsubsection{Relationship with sediment characteristics}

The relationship between $\tau_{0, \text { crit }}$ and the sediment characteristics is shown in Fig. 7. Considering the data collected as a whole, critical entrainment stress was found to depend significantly on dry bulk density (positively) and organic matter (negatively). No relationship was found with median grain size, and in the final multiple regression model, LOI was removed due to its high correlation with organic matter percentage (dry bulk density parameter $=3.0 \times 10^{-4}, \mathrm{p}=$ 0.07 ; organic matter $\%$ parameter $=-1.9 \times 10^{-2}, \mathrm{p}=$ $3 \times 10^{-4}$ ). Erodibility of the sediments appears to be most strongly linked to organic matter content.

Considering the FF data in isolation yielded no significant terms in a multiple regression model, but significant relationships were found in each simple linear regression (dry bulk density: positive, median size: weakly positive, organic matter: negative). Considering the NF data in isolation yielded no significant relationships in simple linear regressions with the sediment characteristic variables.
Table 2. Summary of erosion measurements from far-field (FF) and nearfield (NF) surveys, including critical erosion threshold $\tau_{0, \text { crit }}\left(\mathrm{N} \mathrm{m}^{-2}\right) \mathrm{NA}$ : not available

\begin{tabular}{|c|c|c|c|}
\hline Site & ID & $\begin{array}{c}\mathrm{FF} \tau_{0, \text { crit }}\left(\mathrm{N} \mathrm{m}^{-2} \text { ) }\right. \\
\text { (survey 1; August 2013) }\end{array}$ & $\begin{array}{c}\mathrm{NF} \tau_{0, \text { crit }}\left(\mathrm{N} \mathrm{m}^{-2} \text { ) }\right. \\
\text { (survey 2; May 2014) }\end{array}$ \\
\hline Bloody Bay & ${ }^{*} \_\mathrm{BB}^{*}$ & 0.12 & NA \\
\hline Fiunary & ${ }^{*}{ }^{*}$ FIU ${ }^{*}$ & 0.55 & NA \\
\hline Ardifuir & ${ }^{*}$ _ARD* & 0.31 & NA \\
\hline Durmyon & ${ }^{*}{ }^{*} \mathrm{DUB}{ }^{*}$ & 0.40 & NA \\
\hline Shuna Castle Bay & ${ }^{*} \mathrm{SCB}^{*}$ & 0.17 & 0.02 \\
\hline Bagh Dail Nan Ceann & ${ }^{*} \mathrm{BDNC}^{*}$ & 0.20 & 0.04 \\
\hline Port na Moine & ${ }^{*} \mathrm{PNM}^{*}$ & 0.25 & 0.02 \\
\hline Scallastle & ${ }^{*} \mathrm{SCA}^{*}$ & NA & 0.01 \\
\hline Dunstaffnage & ${ }^{*} \mathrm{DFB}^{*}$ & NA & 0.03 \\
\hline Port na Gille & ${ }^{*}$ _PNG ${ }^{*}$ & NA & 0.02 \\
\hline
\end{tabular}

3.2.4. Resuspension rates of impacted bed material

Data were drawn together from both surveys (NF and FF) to investigate relationships between applied bed stress $\left(\tau_{0}\right)$ and erosion rate $(\varepsilon)$. Although the NF and FF environments differ in their organic content (Fig. 7d), both areas are nonetheless impacted by faecal material, and therefore any expression represents the condition of organically enriched seabeds.

Results of this analysis yielded a wide range of $R^{2}$ values, from $R^{2}=0.29$ (simple 


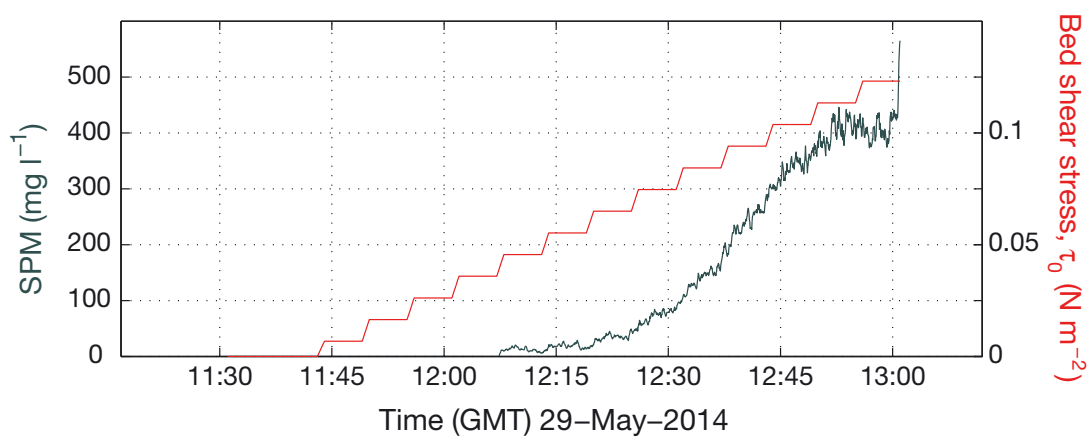

Fig. 6. Suspended particulate matter (SPM) concentration (black) and bed shear stress (red) time series for site 2_DFB2 (near field)
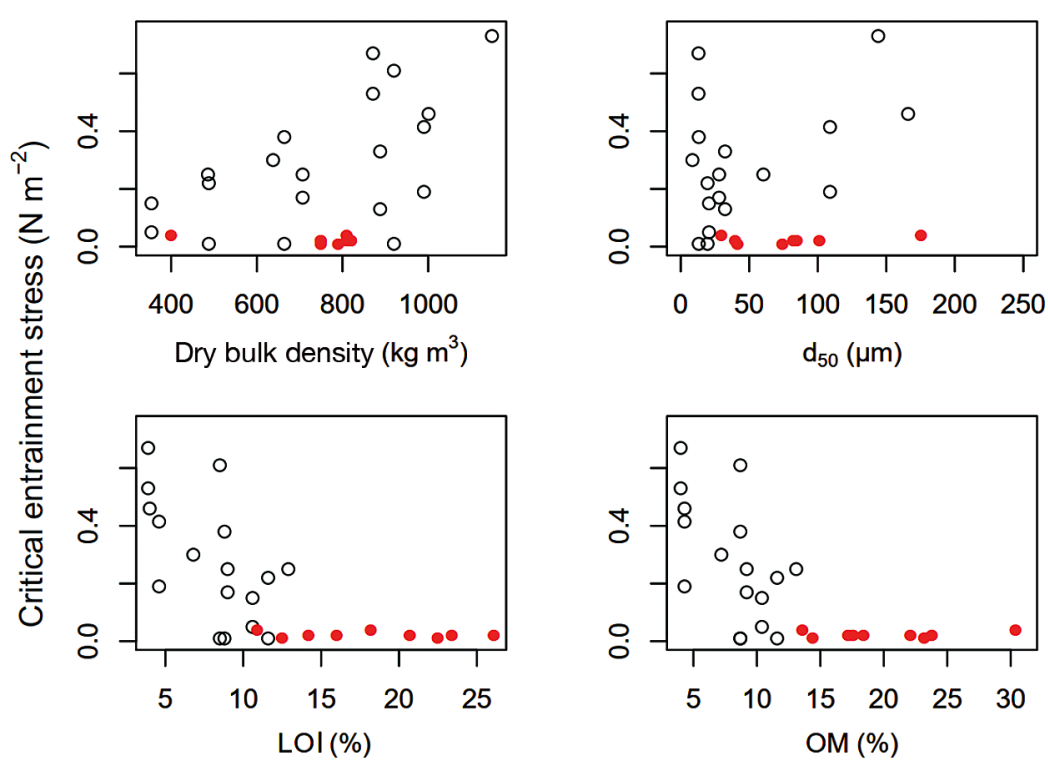

Fig. 7. Relationship between sediment characteristics and critical entrainment stress (open black discs: far-field survey, filled red discs: near-field survey). $\mathrm{d}_{50}$ : median grain size; LOI: loss on ignition; OM: organic matter

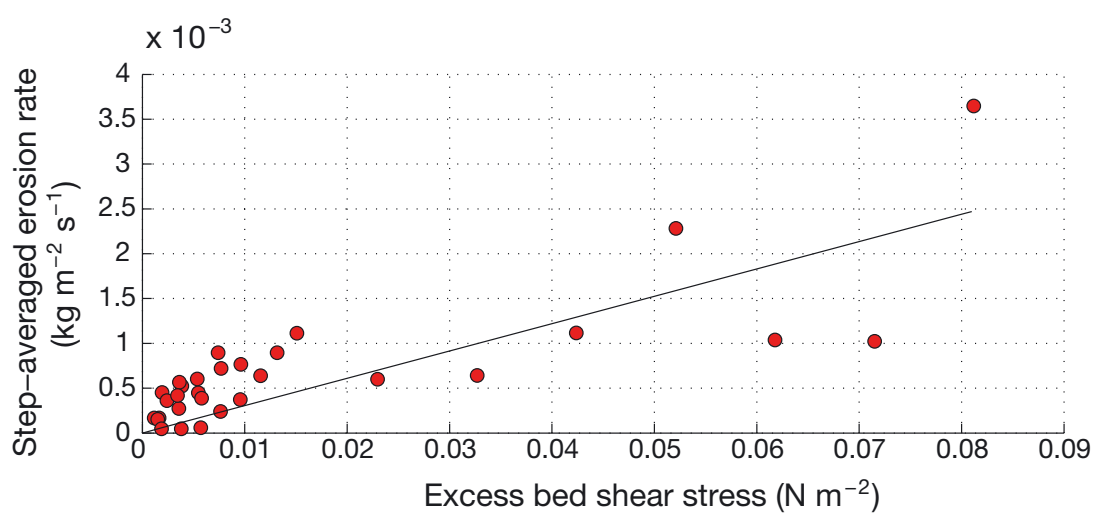

Fig. 8. Excess bed stress $\left(\tau_{0}-\tau_{0, \text { crit }}\right)$ versus erosion rate $\varepsilon$ averaged over each velocity/stress time step on a linear plot dependence on bed stress, $\log \varepsilon$ vs. $\tau_{0}$ ) through $\mathrm{R}^{2}=0.52\left(\varepsilon=0.009\left(\tau_{0}-\tau_{0, \text { crit }}\right)^{0.36}\right)$ to $\mathrm{R}^{2}=0.68\left(\varepsilon=0.031\left(\tau_{0}-\tau_{0, \text { crit }}\right)\right.$, a linear dependence of $\varepsilon$ on the excess bed stress). This latter relationship is shown in Fig. 8.

\section{DISCUSSION}

This work used benthic flumes to make in situ observations to investigate how the characteristics of sediments in the proximity of marine salmon aquaculture farms influence their resuspension, which in turn influences how they interact with water flow to determine transport distances and timescales. The results from this study showed that waste sediments, which are rich in organic matter, are much more easily eroded than the natural sediments on which they fall. This means that they must be parameterised differently in models describing their transport. Our results provide guidance on making this parameterisation. Improving the representation of (deposition and) resuspension in these models using measured datasets allows more accurate predictions of farm footprints to be made and can therefore inform spatial management of the industry (SEPA 2019a). The study described here formed part of the redevelopment of DEPOMOD (Cromey et al. 2002a), a key piece of software used in industry regulation and site planning around the world. The resuspension module within the revised NewDEPOMOD is a compartmentalised model consisting of erosion, transport, deposition and consolidation components. The model uses near-bed current velocity to determine a shear velocity and bed shear stress for each time step. Shear stress then drives a near-bed boundary erosion process in which erosion events are determined by the magnitude of the shear stress above a critical threshold for erosion $\left(\tau_{0, \text { crit }}\right)$, and bed erosion rates $(\varepsilon)$ are moderated by an 
erodibility constant $(M)$. For the model to function optimally, it needs to be provided with values for these parameters.

The magnitude of critical thresholds for resuspension has been a topic of continuous debate (Cromey et al. 2002b) and reiterated the importance of using appropriate information/data to support effective parameterisation. The continuous debate referred to is a function principally of the rather unusual properties of faecal material (which differ substantially from conventional minerogenic sediments in terms of size/density/settling velocity characteristics as well as temporal variation) and the range of tools to measure their hydraulic (erosion) properties with confidence. This creates problems in terms of generating robust data for these parameters, as they cannot be obtained from literature sources (as is the case for sand, for instance); they must be measured.

Several authors (Droppo et al. 2007, Law et al. 2016, Carvajalino-Fernández et al. 2020) quote values for $\tau_{0, \text { crit }}$ which were developed from laboratory experiments. Laboratory studies are useful approaches, particularly for manipulative investigations, to explore a range of facets of material erosion and transport under various highly controlled conditions. However, the fundamental and unavoidable issues with respect to laboratory studies are the changes induced to the material via sampling, preparation and introduction into the laboratory test device, none of which can be quantified. That is not to suggest that laboratorygenerated data are not of use; rather, if sediments can be tested without the necessity of removing them from the seabed, then there is a preservation of aspects of the bio-physical matrix (which govern erosion magnitudes and patterns), such as compaction/ incorporation within the underlying seabed, bioturbation, biogeochemical gradients, disintegration processes, winnowing and interaction with seabed microtopography.

Cromey et al. (2002b) developed a novel approach to determining a field-based (in situ) estimate of $\tau_{0, \text { crit }}$ to support parameterisation of DEPOMOD via a fluorescent UV tracer study. However, this study has received criticism related to the hydraulic similarity of the tracer to real fish farm wastes in the calibration of the resuspension module and for being overly site specific. Novel technology approaches are, however, welcome. Benthic flumes are instruments specifically designed to collect in situ data on bottom boundary erosion parameters, and thus they are ideal instruments to collect this information in the ocean. They have been used for around $30 \mathrm{yr}$ and are considered a mature marine technology, and the wealth of scien- tific data collected to date using these devices means that their operational characteristics are very well understood (Amos et al. 2010). However, their application here is, to the authors' knowledge, a first in aquaculture.

A significant volume of useful data on bottom boundary erosion parameters was collected in this study. In total, 40 successful flume deployments were made encompassing multiple landings at the same site, which allows for an assessment of the spatial variability of parameters. Due to its smaller size, the Voyager I flume can be deployed from a smaller vessel and hence facilitates measurement of sediment erosion properties closer to the fish farm depositional centre at water depths in excess of $40 \mathrm{~m}$. This represents a logistical achievement on sediments which are otherwise very difficult to test. The high-resolution stress profile the flume imparts to bottom sediments allows for a statistical estimate of $\tau_{0, \text { crit }}$. Very close to the fish farm depositional centre, the bottom sediments are highly organically enriched, with LOI percentages commonly in excess of $15 \%$. Values for $\tau_{0, \text { crit }}$ ranged from 0.01 to $0.04 \mathrm{~N} \mathrm{~m}^{-2}$ and are centred on $0.02 \mathrm{~N} \mathrm{~m}^{-2}$. There is a notably low degree of variability between replicate flume drops at a given site (e.g. at SCB 3 replicate runs provide the same $\tau_{0, \text { crit }}$ value), and values were fairly consistent geographically across and between the farm sites. This widespread similarity indicates that the faecal waste deposit layer probably completely smothers the seabed, infilling or nearly infilling any antecedent bottom microtopography. This is an assumption made within NewDEPOMOD and an inference which is also supported by observations of highly similar values for the hydraulic bed roughness $\left(z_{0}\right)$ measured separately across the sites. Law et al. (2016), in a series of laboratory studies examining topographic influence on erosion thresholds, found more variability in $\tau_{0, \text { crit }}$ values, further supporting the hypothesis that substrates in our NF samples were smothered. This is an important distinction, as has been argued elsewhere (Carvajalino-Fernández et al. 2020), that $\tau_{0, \text { crit }}$ should be parameterised according to substrate characteristics but would not be appropriate if the seabed were blanketed by a thick organic layer.

Notwithstanding the issue of artefacts associated with sampling and experimental design, on a general level a comparison of our NF field values with others supports the view that waste faecal material at fish farms (or at least the surficial layers) is a highly organic, high-porosity, normally consolidated and low shear strength (highly erodible) substratum able to be readily resuspended by even comparatively 
low currents. For some NF sites, no erosion threshold was measureable, indicating an exceptionally low strength deposit. Our work suggests a mean value of $0.02 \mathrm{~N} \mathrm{~m}^{-2}$ for the value of the critical entrainment stress for NF impacted sediments, and this value would make a good starting point for models describing aquaculture waste transport on a range of seabed types. For comparison, Law et al. (2016) found values of ca. $0.01 \mathrm{~N} \mathrm{~m}^{-2}$, Droppo et al. (2007) reported 0.06 to $0.1 \mathrm{~N} \mathrm{~m}^{-2}$ and Carvajalino-Fernández et al. (2020) reported values in the range of 0.06 to $0.07 \mathrm{~N} \mathrm{~m}^{-2}$. The critical entrainment stress and corresponding velocities for highly impacted NF sediments, whether in the field or laboratory situations, are much lower than thresholds typically found for other organic marine sediments such as estuarine muds (Amos et al. 1996, 2010, Houwing 1999, Sanford \& Maa 2001). Law \& Hill (2019) found a negative relationship between organic matter and mass eroded (higher erosion threshold at more impacted locations and over time through a production cycle). This may, however, reflect differences in the nature of the sites considered: one of their sites experienced much more wave action than would be expected at those considered here and had very low organic matter percentage in comparison to those in the current study.

Calculated equivalent mean critical current velocities at $2 \mathrm{~m}$ above the seabed were close to the present value within the original AutoDEPOMOD for $\bar{u}_{\text {crit. }}$ at $2 \mathrm{~m}$, which is $0.095 \mathrm{~m} \mathrm{~s}^{-1}$ (Cromey et al. 2002a), and was derived using observations of synthetic fluorescent tracer particles. Tracer particles are expected to erode more readily than bulk sediments, which consist of a mixture of natural and farm-derived material (Cromey \& Black 2005), but our observations of highly enriched sediment matched well. Applying the mean bed roughness measured across the study sites by Black et al. (2016) (0.00003 m, which encompasses the majority of sites here) gives equivalent critical velocities of 0.08 to $0.17 \mathrm{~m} \mathrm{~s}^{-1}$, while using the value found for the less common transitional rough sites gives lower critical velocities of 0.03 to $0.06 \mathrm{~m} \mathrm{~s}^{-1}$.

The larger flume (Voyager II), because it requires a much larger vessel for deployment, was deployed some 200 to $500 \mathrm{~m}$ from the fish farm centre (FF). Bottom sediments were less organically enriched and admixed to varying degrees with local surficial mineral sediments; nonetheless, the sediments may be considered impacted by the farm operations. Critical stress values were all found to be consistently higher by an order of magnitude, and sites with coarser sediments gave values of $\tau_{0, \text { crit }}$ up to $0.74 \mathrm{~N} \mathrm{~m}^{-2}$, indica- tive of a stability gradient with distance from the farms (although there were several instances where no erosion threshold was found, indicating that the initial step was too dramatic or that sediment had not settled properly after the device reached the seabed; Supplement 1). The mean critical erosion stress found for FF samples at our 3 comparison sites (where both $\mathrm{NF}$ and FF surveys were carried out) was $0.19 \mathrm{~N} \mathrm{~m}^{-2}$. While the larger flume used in the FF survey returns values which may be considered conservative, we believe the data reflect genuine differences in bottom stability. The FF and NF surveys were conducted in differing years (a function of project timescales; August and the following May, respectively). This difference in timing potentially affects the state of the seabed (with respect to winter storm action), the point at which sites are in their production cycle (which varied between sites, Law \& Hill 2019), and the temperature and salinity of the overlying water column (which were not collected at the time of the surveys), which may cause some variability in the results. However, on balance we feel the increase in stability with distance from the farm simply reflects a lower mass fraction of faecal material together with a dominating influence of the underlying (more stable, possibly more rough) mineral sediment components. The laboratory observations of Carvajalino-Fernández et al. (2020) suggest that where the seabed is coarser, the resuspension of faeces requires greater bed stresses, a phenomenon referred to by them as substratum dependency. Indeed, in their conclusions they reflect on future efforts to explore linking measured critical shear stresses for lower-impact situations to a continuous variable such as the roughness length $\left(z_{0}\right)$ and eventually to incorporate such complexity within particle transport models via detailed bed feature maps. This is most readily obtained by direct measurement of flow in the bottom boundary layer of the water column (NewDEPOMOD Development Team 2019). Clearly, consideration of the physical reality of the seabed in both the NF and FF is necessary here and should form an important aspect during the development of particle transport models. Bottom video or sediment profile imagery (SPI, Germano et al. 2011), in particular, are useful tools to bring to bear here and are complementary to the methods presented here with respect to understanding waste resuspension processes.

A common drive in (cohesive) sediment research is to correlate the entrainment parameters with more commonly measured bed compositional parameters, such as grain size, organic content and bulk density (Defew et al. 2003). The rationale behind this is to 
explore whether statistically significant relationships may exist with commonly measured bed parameters which could then be used as legitimate proxies for erosion (thereby avoiding the need to measure erosion using benthic flumes) in future studies. We found significant relationships with bulk density (negative) and organic matter percentage (positive) but only when considering data from the 2 surveys together. However, erosion resistance is a multiparametric issue. No single variable accounts for surface cohesive strength; this is particularly true for organically enriched sediments where highly cohesive/adhesive bacteria thrive, binding sediments together (Black et al. 2002).

Boundary shear stress is defined as the force per unit of area that flowing water exerts on the seabed. Particles at the surface of the seabed move when the downstream (fluid drag) and upward (fluid lift) forces overcome the forces keeping a particle in contact with the bed (Wiberg \& Smith 1987). The critical entrainment stress is relevant to the incipient motion of surficial material, whereas continued seabed erosion above $\tau_{0 \text {,crit }}$ acts to sequentially excavate sub-surface horizons, the so-called mass flux. As erosion proceeds in the benthic flume annulus, the system records the mass flux for each stress step, and therefore benthic flumes are suited to provide crucial data to allow modellers to develop bed erosion formulations needed within modules to provide for resuspension processes.

Our results suggested the use of a linear relationship between erosion rate and excess bed shear stress to parameterise benthic flux at the seabed for impacted seabed areas, with an erodibility constant $M=0.031 \mathrm{~kg} \mathrm{~m}^{-2} \mathrm{~s}^{-1}$. A broad range of different formulations have been published for this relationship for normal cohesive (mudflat) sediments (Mehta \& Parchure 2000) in addition to efforts to unify different erosion types within a single formulation (Sanford \& Maa 2001). An inherent facet of natural biologically active sediment deposits is high local variability in specific characteristics, limiting the quality of fit of any relationship (Amos et al. 2010). Nonetheless, linear relationships have been found by various previous studies to adequately parameterise benthic flux for fine-grained, cohesive sediments (Kandiah 1974, Ariathurai \& Arulanandan 1978, Delo 1988), with quoted values for $M$ coefficients on the order of $10^{-4}$ (Mitchener \& Torfs 1996) to $10^{-3} \mathrm{~kg} \mathrm{~m}^{-2} \mathrm{~s}^{-1}$ (Owen 1975). Our fitted value was $10^{-2}$, indicating that the erosion rate for waste solids increases much more quickly once past the critical erosion threshold.

\section{CONCLUSIONS}

Carvajalino-Fernández et al. (2020) noted only this year that the 'current body of literature concerning remobilisation processes for fish faeces is, unfortunately, very limited'. This study was aimed towards improving this situation, via the collection of new field data at a range of geographically disparate sites on the Scottish west coast. The application here of benthic flume technology, which is not new in terms of marine instrumentation but which has hitherto not been adopted by the aquaculture community or researchers, is a positive step forwards. Flumes are ideally suited to this application. We have demonstrated how direct measures of the important bottom boundary layer erosion parameters can be collected relatively quickly and simply, even in areas traditionally difficult to access such as near the depositional centre of farms, and illustrated how a technology-led approach can be used to ultimately update particle transport models for faecal waste. Typically, 3 to 4 flume deployments can be made from a vessel working $12 \mathrm{~h}$ days, enabling collection as here of a sizeable dataset in a relatively short time frame and encompassing some level of replication (useful in the assessment of heterogeneity). Amos et al. (1992b) published a design for the larger Voyager II flume, and these principles carried over to Voyager I, which was made in-house. Flumes are also available commercially (see www.kcdenmark.com). It should, therefore, be possible for other researchers and the industry itself to use this particular technology to continue research into this area.

The application of flume technology has provided updated estimates of the critical entrainment stress $\left(\tau_{0, \text { crit }}\right)$ and the erosion rate formulation to NewDEPOMOD. Cromey et al. (2002b) remains the only field-based study which provides a value for the critical shear stress value to the DEPOMOD model. The value determined here was, interestingly, the same as Cromey's. The laboratory studies noted previously also found values highly similar to this. Collectively, these findings lend weight to implementation of this mean value within NewDEPOMOD. The benthic flux expression provides an updated value for $M$ $\left(0.031 \mathrm{~kg} \mathrm{~m}^{-2} \mathrm{~s}^{-1}\right)$, derived in this instance from 40 successful flume drops. This, in conjunction with the linear excess stress formulation, is implemented within the NewDEPOMOD model.

The main goal of this study was to collect data at a range of sites rather than to target deployments at, or onto, specific problems. However, it is relatively straightforward to address specific areas using the 
flume approach. This work provides new field values for $\tau_{0, \text { crit }}$ and the $\varepsilon-\tau_{0}$ relationship and represents a development on previous laboratory datasets. Nonetheless, in reality these parameters likely vary temporally, and a constant value status quo as present is perhaps an oversimplification of the topic. Future improvement to models through incorporation of multiple (or time/space varying) erosion parameters is widely regarded as the next step in the evolution of particle transport models within aquaculture. Video surveys in salmon farming sites have shown there is a time-varying change in faecal material as it degrades from intact pellets to bottom broken-down faeces, a function of very near bed turbulent shearing, grazing by benthic organisms, and the cumulative effect of short-lived resuspension/settling episodes rather than swelling or thermal or bacterial degradation (Carvajalino-Fernández et al. 2020). These processes will likely impart the critical shear stress required to resuspend them. Such variability could be examined, in conjunction with other techniques such as SPI, through an appropriate survey design and timing of flume deployments. Similarly, biofilms may grow on the surface of waste mounds during summer (Droppo et al. 2007), generating a longer-term signal in bed stability. Summer vs. winter flume studies could expose such a signal if biostabilisation processes were pronounced. On a related basis, winter wave effects may erode a mound down to a horizon which is much less erodible, thereby limiting ongoing resuspension; again, this could be proven through the use of flume and related technology and appropriate survey planning.

Model algorithms may omit some aspects of reality while also introducing numerical formulations and parameters which do not necessarily relate directly to real processes. As such, these parameters could also act as candidates for tuning predicted footprints to observational data (R. J. Weeks et al. unpubl.), while recent work investigating the time evolution of sediments and degradation of farm wastes (Bravo \& Grant 2018) gives insight into how some such additional processes may be accounted for as models are developed further and adapted to different regulatory regimes. Refining transport parameters and future model validation using the methods applied here will help increase our understanding and predictive capacity of waste transport to the FF and help understand wider environmental impacts.

Acknowledgements. Saul Reynolds, Partrac Ltd., and Thom Nickell, SAMS, participated on the benthic flume cruises. Carl Amos contributed to writing up the original internal report and recommendations. We acknowledge the support of the masters and crews of the RVs 'Sir John Murray', 'Calanus' and 'Seol Mara' and are grateful to the farmers for access to their sites. This work was funded by the Scottish Government (grant number SAM/004/12) and the Scottish Aquaculture Innovation Centre in conjunction with the Scottish Salmon Producers Organisation (ExPAND project). The work was overseen by representatives from Marine Scotland, Marine Scotland Science, SEPA, and the Crown Estate. The manuscript was substantially improved thanks to the comments of 3 anonymous reviewers.

\section{LITERATURE CITED}

Adams TP, Aleynik D, Black KD (2016) Temporal variability in sea lice population connectivity and implications for regional management protocols. Aquacult Environ Interact 8:585-596

Amos CL, Daborn GR, Christian HA, Atkinson A, Robertson A (1992a) In situ erosion measurements on fine-grained sediments from the Bay of Fundy. Mar Geol 108:175-196

Amos CL, Grant J, Daborn GR, Black K (1992b) Sea carousel-a benthic, annular flume. Estuar Coast Shelf Sci 34:557-577

Amos CL, Sutherland TF, Zevenhuizen J (1996) The stability of sublittoral, fine-grained sediments in a subarctic estuary. Sedimentology 43:1-19

Amos CL, Bergamasco A, Umgiesser G, Cappucci S and others (2004) The stability of tidal flats in Venice Lagoonthe results of in-situ measurements using two benthic, annular flumes. J Mar Syst 51:211-241

Amos CL, Umgiesser G, Ferrarin C, Thompson CEL, Whitehouse RJS, Sutherland TF, Bergamasco A (2010) The erosion rates of cohesive sediments in Venice lagoon, Italy. Cont Shelf Res 30:859-870

Ariathurai R, Arulanandan K (1978) Erosion rates of cohesive soils. J Hydraul Div 104:279-283

Bahr DB, Hutton EWH, Syvitski JPM, Pratson LF (2001) Exponential approximations to compacted sediment porosity profiles. Comput Geosci 27:691-700

* Bannister RJ, Johnsen IA, Hansen PK, Kutti T, Asplin L (2016) Near- and far-field dispersal modelling of organic waste from Atlantic salmon aquaculture in fjord systems. ICES J Mar Sci 73:2408-2419

Black K, Cramp A (1995) A device to examine the in situ response of intertidal cohesive sediment deposits to fluid shear. Cont Shelf Res 15:1945-1954

Black KS, Paterson DM (1997) Measurement of the erosion potential of cohesive marine sediments: a review of current in situ technology. J Mar Environ Eng 26:43-83

Black KS, Tolhurst TJ, Paterson DM, Hagerthey SE (2002) Working with natural cohesive sediments. J Hydraul Eng 128:2-8

Black KD, Carpenter T, Berkeley A, Black K, Amos C (2016) Refining sea-bed process models for aquaculture. New DEPOMOD Final Report, SAM/004/12. Scottish Association for Marine Science, Oban

* Bloodworth JW, Baptie MC, Preedy KF, Best J (2019) Negative effects of the sea lice therapeutant emamectin benzoate at low concentrations on benthic communities around Scottish fish farms. Sci Total Environ 669:91-102

Bravo F, Grant J (2018) Modelling sediment assimilative capacity and organic carbon degradation efficiency at marine fish farms. Aquacult Environ Interact 10:309-328 
Broch OJ, Daae RL, Ellingsen IH, Nepstad R, Bendiksen EÅ, Reed JL, Senneset G (2017) Spatiotemporal dispersal and deposition of fish farm wastes: a model study from central Norway. Front Mar Sci 4:199

Carvajalino-Fernández MA, Keeley NB, Fer I, Law BA, Bannister RJ (2020) Effect of substrate type and pellet age on the resuspension of Atlantic salmon faecal material. Aquacult Environ Interact 12:117-129

Chang BD, Page FH, Losier RJ, McCurdy EP (2014) Organic enrichment at salmon farms in the Bay of Fundy, Canada: DEPOMOD predictions versus observed sediment sulfide concentrations. Aquacult Environ Interact 5: 185-208

Cromey CJ, Black KD (2005) Modelling the impacts of finfish aquaculture. In: Hargrave BT (ed) Environmental effects of marine finfish aquaculture. Handbook of Environmental Chemistry, Vol 5M. Springer, Berlin, p 129-155

* Cromey CJ, Nickell TD, Black KD (2002a) DEPOMODmodelling the deposition and biological effects of waste solids from marine cage farms. Aquaculture 214: 211-239

* Cromey CJ, Nickell TD, Black KD, Provost PG, Griffiths CR (2002b) Validation of a fish farm waste resuspension model by use of a particulate tracer discharged from a point source in a coastal environment. Estuaries Coasts 25:916-929

Cromey CJ, Thetmeyer H, Lampadariou N, Black KD, Kögeler J, Karakassis I (2012) MERAMOD: predicting the deposition and benthic impact of aquaculture in the eastern Mediterranean Sea. Aquacult Environ Interact 2:157-176

Defew EC, Tolhurst TJ, Paterson DM, Hagerthey SE (2003) Can the stability of intertidal sediments be predicted from proxy parameters? An in situ investigation. In: Raffaelli D, Solan M, Paterson DM, Buck AL, Pomfret JR (eds) Coastal zone topics 5: the estuaries and coasts of north-east Scotland. Estuarine and Coastal Sciences Association, Aberdeen, p 61-70

Delo EA (1988) Deposition of cohesive sediment from flowing water. Rep no. SR 152. Hydraulics Research, Wallingford

Droppo IG, Jaskot C, Nelson T, Milne J, Charlton M (2007) Aquaculture waste sediment stability: implications for waste migration. Water Air Soil Pollut 183:59-68

Gentry RR, Lester SE, Kappel CV, White C, Bell TW, Stevens J, Gaines SD (2017) Offshore aquaculture: spatial planning principles for sustainable development. Ecol Evol 7: 733-743

Germano JD, Rhoads DC, Valente RM, Carey DA, Solan M (2011) The use of sediment profile imaging (SPI) for environmental impact assessments and monitoring studies: lessons learned from the past four decades. Oceanogr Mar Biol Annu Rev 49:235-298

* Giles H, Broekhuizen N, Bryan KR, Pilditch CA (2009) Modelling the dispersal of biodeposits from mussel farms: the importance of simulating biodeposit erosion and decay. Aquaculture 291:168-178

Hargrave BT, Holmer M, Newcombe CP (2008) Towards a classification of organic enrichment in marine sediments based on biogeochemical indicators. Mar Pollut Bull 56: 810-824

Houwing EJ (1999) Determination of the critical erosion threshold of cohesive sediments on intertidal mudflats along the Dutch Wadden Sea coast. Estuar Coast Shelf Sci 49:545-555

Kalantzi I, Karakassis I (2006) Benthic impacts of fish farm- ing: meta-analysis of community and geochemical data. Mar Pollut Bull 52:484-493

Kandiah A (1974) Fundamental aspects of surface erosion of cohesive soils. University of California, Davis, CA

Keeley NB, Cromey CJ, Goodwin EO, Gibbs MT, Macleod CM (2013) Predictive depositional modelling (DEPOMOD) of the interactive effect of current flow and resuspension on ecological impacts beneath salmon farms. Aquacult Environ Interact 3:275-291

Kusuda T, Umita T, Koga K, Futawatari T, Awaya Y (1985) Erosional process of cohesive sediments. Water Sci Technol 17:891-901

Kavelle JW, Mofjeld HO (1987) Do critical stresses for incipient motion and erosion really exist? J Hydraul Eng 113: 370-385

Law BA, Hill PS (2019) Spatial and temporal variation in cumulative mass eroded and organic matter percentage in surface sediments near areas of active salmon aquaculture. Aquacult Environ Interact 11:305-320

K Law BA, Hill PS, Milligan TG, Zions V (2016) Erodibility of aquaculture waste from different bottom substrates. Aquacult Environ Interact 8:575-584

K Lee S, Hartstein ND, Jeffs A (2015) Modelling carbon deposition and dissolved nitrogen discharge from sea cage aquaculture of tropical spiny lobster. ICES J Mar Sci 72: i260-i275

Loh PS (2005) An assessment of the contribution of terrestrial organic matter to total organic matter in sediments in Scottish sea lochs. PhD thesis, The Open University, Milton Keynes

* Masaló I, Guadayol Ò, Peters F, Oca J (2008) Analysis of sedimentation and resuspension processes of aquaculture biosolids using an oscillating grid. Aquacult Eng 38: 135-144

Mehta AJ, Parchure TM (2000) Surface erosion of finegrained sediment revisited. In: Flemming BW, Delafontaine MT, Liebezeit G (eds) Muddy coast dynamics and resource management. Elsevier, Amsterdam, p 55-74

Mehta AJ, Partheniades E (1979) Kaolinite resuspension properties. J Hydraul Div 105:411-416

Mehta AJ, Partheniades E (1982) Resuspension of deposited cohesive sediment beds. Coast Eng Proc 1(18):95

Mitchener H, Torfs H (1996) Erosion of mud/sand mixtures. Coast Eng 29:1-25

*Mudroch A, Azcue JM (1995) Manual of aquatic sediment sampling. CRC Press, Boca Raton, FL. https://www. routledge.com/Manual-of-Aquatic-Sediment-Sampling/ Mudroch-Azcue/p/book/978156670029

NewDEPOMOD Development Team (2019) DEPOMOD. Scottish Association for Marine Science, Oban. https:// depomod.sams.ac.uk/ (accessed 17 Sep 2020)

Niklitschek EJ, Soto D, Lafon A, Molinet C, Toledo P (2013) Southward expansion of the Chilean salmon industry in the Patagonian fjords: main environmental challenges. Rev Aquacult 5:172-195

Owen MW (1975) Erosion of Avonmouth mud. Hydraulics Research Station, Wallingford

Pearson TH, Rosenberg R (1978) Macrobenthic succession in relation to organic enrichment and pollution of the marine environment. Oceanogr Mar Biol Annu Rev 16:229-311

Rhoads DC, Boyer LF (1982) The effects of marine benthos on physical properties of sediments: a successional perspective. In: McCall PL, Tevesz MJS (eds) Animal-sediment relations: the biogenic alteration of sediments. Springer, New York, NY, p 3-52 
Salama NKG, Rabe B (2013) Developing models for investigating the environmental transmission of diseasecausing agents within open-cage salmon aquaculture. Aquacult Environ Interact 4:91-115

Sandvik AD, Bjørn PA, Ådlandsvik B, Asplin L and others (2016) Toward a model-based prediction system for salmon lice infestation pressure. Aquacult Environ Interact 8:527-542

Sanford LP, Maa JPY (2001) A unified erosion formulation for fine sediments. Mar Geol 179:9-23

Scotland Food \& Drink (2017) Aquaculture Growth to 2030: a strategic plan for farming Scotland's seas. Scotland Food and Drink, Edinburgh. https://foodanddrink.uk/ resources/sector-strategies/aquaculture-growth-to-2030 -a-strategic-plan-for-farming-scotland-s-seas/ (accessed 17 Sep 2020)

SEPA (Scottish Environment Protection Agency) (2019a) Aquaculture modelling: regulatory modelling guidance for the aquaculture sector. SEPA, https://www.sepa.org.uk/ media/450279/regulatory-modelling-guidance-for-theaquaculture-sector.pdf

SEPA (2019b) Protection of the marine environment: discharges from marine pen fish farms, a strengthened regulatory framework. SEPA, https://www.sepa.org.uk/media/ 433439/finfish-aquaculture-annex-2019_31052019.pdf

Shields A (1936) Anwendung der Ähnlichkeitsmechanik und der Turbulenzforschung auf die Geschiebebewegung. Preussische Versuchsanstalt Wasserbau Schiffbau, Berlin

Sutherland TF, Amos CL, Grant J (1998a) The effect of buoyant biofilms on the erodibility of sublittoral sediments of a temperate microtidal estuary. Limnol Oceanogr 43: 225-235

Sutherland TF, Amos CL, Grant J (1998b) The erosion threshold of biotic sediments: a comparison of methods. Spec Publ Geol Soc Lond 139:295-307

Sutherland TF, Amos CL, Ridley C, Droppo IG, Petersen SA (2006) The settling behavior and benthic transport of fish feed pellets under steady flows. Estuaries Coasts 29: $810-819$

Tett P, Verspoor E, Hunter DC, Coulson M and others (2018)

Editorial responsibility: Jonathan Grant,

Halifax, Nova Scotia, Canada
Review of the environmental impacts of salmon farming in Scotland. http://www.parliament.scot/parliamentarybusiness/CurrentCommittees/107588.aspx

* Thompson CEL, Couceiro F, Fones GR, Helsby R and others (2011) In situ flume measurements of resuspension in the North Sea. Estuar Coast Shelf Sci 94:77-88

Thorn MFC, Parsons JG (1980) Erosion of cohesive sediments in estuaries: an engineering guide. In: Stephens HS (ed) Proc 3rd Int Symp Dredg Technol, Bordeaux, 5-7 March 1980. BRHA Fluid Engineering, Cranfield, p 349-358

Veldhoen N, Ikonomou MG, Buday C, Jordan J and others (2012) Biological effects of the anti-parasitic chemotherapeutant emamectin benzoate on a non-target crustacean, the spot prawn (Pandalus platyceros Brandt, 1851) under laboratory conditions. Aquat Toxicol 108:94-105

Villaret C, Paulic M (1986) Experiments on the erosion of deposited and placed cohesive sediments in an annular flume and a rocking flume. Rep UFL/COEL-86/007. Coastal and Oceanographic Engineering Department, University of Florida, Gainesville, FL

WWeise AM, Cromey CJ, Callier MD, Archambault P, Chamberlain J, McKindsey CW (2009) Shellfish-DEPOMOD: modelling the biodeposition from suspended shellfish aquaculture and assessing benthic effects. Aquaculture 288:239-253

Wiberg PL, Smith JD (1987) Calculations of the critical shear stress for motion of uniform and heterogeneous sediments. Water Resour Res 23:1471-1480

Widdows J, Brinsley M, Elliott M (1998) Use of in situ flume to quantify particle flux (biodeposition rates and sediment erosion) for an intertidal mudflat in relation to changes in current velocity and benthic macrofauna. Spec Publ Geol Soc Lond 139:85-97

Widdows J, Friend PL, Bale AJ, Brinsley MD, Pope ND, Thompson CEL (2007) Inter-comparison between five devices for determining erodability of intertidal sediments. Cont Shelf Res 27:1174-1189

World Bank (2013) Fish to 2030: prospects for fisheries and aquaculture. Agriculture and environmental services discussion paper no. 3. World Bank, Washington, DC

Submitted: December 17, 2019; Accepted: July 14, 2020

Proofs received from author(s): September 17, 2020 